\title{
Study on Alkaline Flooding System with Antiscaling Effect
}

\author{
Tang Mingguang, Liu Qinghua, Zhang Fengbo, Wang Shichao, Lu Ruibin \\ Research Institute of Western South China Sea Petroleum Administrative Bureau, CNOOC Zhanjiang Branch, Zhanjiang, China
}

\section{Email address:}

tangmg@cnooc.com.cn (Tang Mingguang), liuqh20@cnooc.com.cn (Liu Qinghua), zhangfb@cnooc.com.cn (Zhang Fengbo), wangshzh18@cnooc.com.cn (Wang Shichao), lurb4@cnooc.com.cn (Lu Ruibin)

\section{To cite this article:}

Tang Mingguang, Liu Qinghua, Zhang Fengbo, Wang Shichao, Lu Ruibin. Study on Alkaline Flooding System with Antiscaling Effect. International Journal of Oil, Gas and Coal Engineering. Vol. 5, No. 3, 2017, pp. 34-38. doi: 10.11648/j.ogce.20170503.12

Received: March 27, 2017; Accepted: April 8, 2017; Published: May 24, 2017

\begin{abstract}
For scaling problem in the alkaline flooding, the alkali with anti scaling effect was researched. The results show that scale inhibition effect of PAPEMP alkaline system (containing polyamino polyether methylene phosphonae, $\mathrm{NaOH} \mathrm{NaBO}_{2}$ ) is better than PASP alkaline system (containing sodium of polyaspartic acid, $\mathrm{NaOH}, \mathrm{NaBO}_{2}$ ), When the concentration of the PAPEMP alkaline system is larger than $4 \%$, it could tolerate the solution with calcium ion concentration of $500 \mathrm{mg} / \mathrm{L}$ without scaling; both $\mathrm{NaBO}_{2}$ and PAPEMP alkaline system have good displacement efficiency. During the displacement process, a large differential pressure response appears when alkali concentration is high, and the incremental oil recovery increases with the increase of alkaline concentration. Microscopic mechanisms show that the alkaline solution penetrates into the crude oil and water drops are formed inside the oil phase, subsequently, to turn into the W/O emulsion, which could block the water channel and inhibit the viscous fingering, leading to the improvement of sweep efficiency.
\end{abstract}

Keywords: Alkaline Flooding, Anti Scaling Effect, Enhance Oil Recovery, Microscopic Mechanism

\section{Introduction}

China has abundant heavy oil resources, among which $30.1 \%$ are developed by water flooding. However, the recovery efficiency of these water-flooded heavy oil reserves is at least $10 \%$ lower than that of conventional oil reserves because of the adverse mobility ratio between oil and water [1]. Therefore, it is a technical problem about how to further enhance the oil recovery of the heavy oil reservoirs. Thermal recovery is a feasible method since it could decrease the water-oil mobility ratio by reduces the viscosity of oil. Nonetheless, when the oil is thin and shallow, the heat loss would be very serious, making it unsuitable to implement thermal recovery. Both the domestic and foreign research shows that chemical flooding is an important replace method $[2,3]$.

Due to the low cost of alkaline agent and its notable ability to enhance heavy oil recovery in the laboratory test, more attention are paid to alkaline flooding. Heavy oil frequently has a high acid number, and alkali can react with the organic acids in the oil to generate in-situ surfactants at the oil-water surfaces to decrease the interfacial tension (IFT) and emulsify the oil.
Arhuoma et al. [4] investigated the relationship between the pressure drop and the oil recovery by alkali flooding in a heavy oil reservoir. The test indicated that the pressure drop increased with the alkaline concentration; it was also observed that the output liquid was a high viscosity $\mathrm{W} / \mathrm{O}$ emulsion. $\mathrm{W} / \mathrm{O}$ emulsions can block the high permeability zone and improve the sweep efficiency, and the oil recovery is improved as a result of the increase in the pressure drop.

$\mathrm{NaOH}$ and $\mathrm{Na}_{2} \mathrm{CO}_{3}$ are commonly used alkali for alkaline flooding. But when the concentration of the calcium and magnesium ions in the formation water is high, scaling would occur and the alkaline consumption would be significant, affecting the injection and displacing effect. Jennings et al. [5] concluded that hard water containing $\mathrm{Ca}^{2+}$ could inactivate the surfactant, and therefore $\mathrm{Ca}^{2+}$ needed to be removed when the solutions were prepared. An organic alkaline represents a good chelating agent and has a strong chelating capacity for calcium and magnesium ions. Berger and Lee [6] changed the inorganic alkali to organic alkali in ASP flooding and investigated the effects of the organic alkali on the interfacial tension, viscosity, and adsorption of OASP (combination flooding with organic base). It was found that the organic alkali was not influenced by water hardness and could improve polymer performance in hard water. Therefore, it 
becomes particularly important to find an anti-scaling alkaline flooding system.

$\mathrm{NaBO}_{2}$ has strong calcium and magnesium ion resistance [7 9]. Flaaten et al. found that a surfactant formulation in hard brine with the inclusion of sodium metaborate performed well in core floods with high oil recovery. Zhang et al. observed that sodium metaborate provided comparable performance to sodium carbonate in enhancing the oil recovery and altering the rock surface chemistry, whereas sodium metaborate showed a greater potential than sodium carbonate in EOR applications. However, the alkalinity of pure sodium metaborate is very weak. For this reason, we should find a flooding system which could have both high $\mathrm{pH}$ and anti-scaling ability. One important method is to add chemical antiscale agent. In this paper, two chemical antiscale agents are selected to compound with alkaline to evaluate the antiscaling ability. The displacing efficiency and mechanism are then investigated for the system which has favorbale antiscaling effect.

\section{Experimental Section}

\subsection{Fluids and Chemicals}

The oil used in the experiment is Xia- 8 heavy oil from the Shengli oilfield, and its basic properties are shown in Table 1. All solutions in the experiment are prepared with formation water. The synthetic formation is made according to the Table 2. The two anti-scaling agents are polyaspartic acid (sodium) PASP and Polyamino Polyether Methylene Phosphonate (PAPEMP). The solid content of these two agents is higher than $40 \%$.

Table 1. Basic Properties of Heavy Oil.

\begin{tabular}{llll}
\hline heavy oil & $\begin{array}{l}\text { density at } \mathbf{5 0}^{\circ} \mathbf{C} \\
\left(\mathbf{g} / \mathbf{c m}^{3}\right)\end{array}$ & $\begin{array}{l}\text { viscosity at } \\
\mathbf{5 0}^{\circ} \mathbf{C}(\mathbf{m P a})\end{array}$ & $\begin{array}{l}\text { acid number (mg of } \\
\text { KOH/g of sample) }\end{array}$ \\
\hline Xia-8 & 0.9712 & 3950 & 4.66 \\
\hline
\end{tabular}

Table 2. Ionic composition of the formation water.

\begin{tabular}{llllll}
\hline \multicolumn{2}{l}{ Ion concentration $(\mathbf{m g} / \mathbf{L})$} & & & \multicolumn{1}{c}{ Total salinity (mg/L) } \\
\hline $\mathrm{Cl}^{-}$ & $\mathrm{HCO}_{3}{ }^{-}$ & $\mathrm{Ca}^{2+}$ & $\mathrm{Mg}^{2+}$ & $\mathrm{Na}^{+}\left(\mathrm{K}^{+}\right)$ & 13659.9 \\
8118.5 & 248.2 & 146.7 & 49 & 5097.5 & \\
\hline
\end{tabular}

\subsection{Preparation of Antiscale System}

The mother liquid of the antiscale system consists of $10 \mathrm{~g}$ antiscale agent, $10 \mathrm{~g}$ sodium metaborate, $1 \mathrm{~g} \mathrm{NaOH}$ and $29 \mathrm{~g}$ water, and that containing polyaspartic acid (sodium) or Polyamino Polyether Methylene Phosphonate is named PASP alkaline system or PAPEMP alkaline system.

\subsection{Sandpack Flooding Test}

The length and diameter of sandpacks respectively is $30 \mathrm{~cm}$, $2.6 \mathrm{~cm}$. The sandpacks were wet-packed as follows: first, cleaned and dried quartz sand, 100-120 and 80-100 mesh, was mixed at a weight ratio of $3: 1$. Next, a large amount of sand and formation water were added to the tube and the tube was slightly vibrated. During the process, the water surface should be kept above the sand surface to prevent air from entering the sand. The sandpack displacement was conducted horizontally at $50^{\circ} \mathrm{C}$. The procedure is as follows: (1) At first, the sandpack is saturated with formation water and then the permeability is measured and the porosity is calculated.(2) Heavy oil is injected into the sandpack until the water cut is less than $2 \%$, and the oil saturation can be gained. (3) The sandpack is water flooded until the oil cut is less than $2 \%$, and a chemical slug of 0.3 pore volume is injected, followed by an extended waterflooding until the oil production becomes negligible(when the oil cut was less than 2\%). No special circumstances, formation water and chemical slug is injected with $0.5 \mathrm{ml} / \mathrm{min}$.

The equipment for the sandpack flooding is shown in Figure 1.

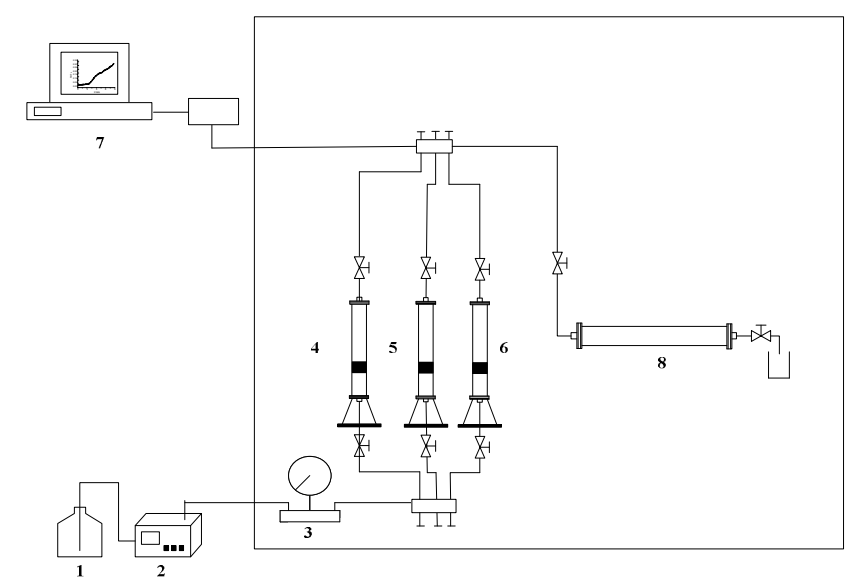

Figure 1. The equipment for sandpack flooding (1-distilled water, 2-pump, 3-pressure meter, 4-formation brine container, 5-crude oil container, 6-chemical agent container, 7-pressure collection system, 8-sandpack model).

\subsection{Micromodel Test}

The steps for the micromodel test are as follows: (1) the micromodel is evacuated; (2) the micromodel is saturated with formation water; (3) oil is injected; (4) chemical flooding at $0.003 \mathrm{~mL} / \mathrm{min}$ is conducted, and all of the dynamic processes are videotaped; (5) the collected images are analyzed. To observe the phenomena during the flooding easily, $0.05 \mathrm{wt} \%$ eosin is added to the aqueous solution. The micromodel is hydrophilic, and the pore volume and porosity are $0.012 \mathrm{ml}$ and $36.83 \%$, respectively.

\section{Results and Discussion}

Firstly, the antiscale capacity of PASP alkaline system and PAPEMP alkaline system was evaluated under the condition of $50^{\circ} \mathrm{C}$, Then to study the oil displacement effect and mechanism of alkaline system with sandpack flooding experiments.

\subsection{The Antiscaling Effect of the PASP Alkaline System}

The antiscaling effect of the PASP alkaline systems was showed in Table 3. The results indicate that for the antiscaling solution with concentration of $1 \%$, the antiscale effect is good when the calcium concentration in the formation water is 
lower than $200 \mathrm{mg} / \mathrm{L}$; for the antiscaling solution with concentration of $2 \%$, the antiscale effect is good when the calcium concentration in the formation water is lower than $300 \mathrm{mg} / \mathrm{L}$ and the antiscale solution with concentration of $4 \%$ have no antiscaling effect. In the whole, the antiscaling effect of the PASP alkaline system is general. The antiscaling effect decreases with the increase of the calcium concentration, while the effect of the antiscale solution has no direct proportion with its concentration.

Table 3. Antiscale effect of PASP system.

\begin{tabular}{llll}
\hline \multirow{2}{*}{$\begin{array}{l}\mathbf{C a}^{2+} \text { concentration } \\
\mathbf{m g} / \mathbf{L}\end{array}$} & \multicolumn{3}{l}{$\begin{array}{l}\text { Mass concentration of the PASP alkaline } \\
\text { systems in the solution }\end{array}$} \\
\cline { 2 - 4 } & $\mathbf{1 \%}$ & $\mathbf{2 \%}$ & $\mathbf{4 \%}$ \\
\hline 50 & no scaling & no scaling & scaling \\
100 & no scaling & no scaling & scaling \\
200 & no scaling & no scaling & scaling \\
300 & scaling & no scaling & scaling \\
400 & scaling & scaling & scaling \\
500 & scaling & scaling & scaling \\
\hline
\end{tabular}

Table 4. Antiscale effect of PAPEMP system.

\begin{tabular}{|c|c|c|c|c|c|c|c|}
\hline \multirow{2}{*}{$\begin{array}{l}\mathrm{Ca}^{2+} \text { concentration } \\
\mathrm{mg} / \mathrm{L}\end{array}$} & \multicolumn{7}{|c|}{ Mass concentration of the PASP alkaline systems in the solution } \\
\hline & $1 \%$ & $2 \%$ & $3 \%$ & $4 \%$ & $5 \%$ & $8 \%$ & $10 \%$ \\
\hline 50 & no scaling & no scaling & no scaling & no scaling & no scaling & no scaling & no scaling \\
\hline 100 & no scaling & no scaling & no scaling & no scaling & no scaling & no scaling & no scaling \\
\hline 200 & no scaling & no scaling & no scaling & no scaling & no scaling & no scaling & no scaling \\
\hline 300 & scaling & no scaling & no scaling & no scaling & no scaling & no scaling & no scaling \\
\hline 400 & scaling & scaling & no scaling & no scaling & no scaling & no scaling & no scaling \\
\hline 500 & scaling & scaling & scaling & no scaling & no scaling & no scaling & no scaling \\
\hline
\end{tabular}

\subsection{Oil Displacement Effect and Mechanism of the PAPEMP Alkaline System}

Eleven groups of sandpack flooding experiments were conducted in the laboratory to investigate the displacement effects of $\mathrm{NaBO}_{2}$ solution and the PAPEMP alkaline system with wt $\%(1 \%, 2 \%, 3 \%, 5 \%, 7 \%$ and 9\%, represented by specific component in the table 5 .

Table 5. Summaries of the sandpack flooding test.

\begin{tabular}{|c|c|c|c|c|c|c|c|}
\hline \multirow{2}{*}{$\begin{array}{l}\text { Run } \\
\text { no. }\end{array}$} & \multirow[b]{2}{*}{$\begin{array}{l}\text { Porosity } \\
(\%)\end{array}$} & \multirow[b]{2}{*}{$\begin{array}{l}\text { Permeability } \\
\left(10^{-3} \mu \mathrm{m}^{2}\right)\end{array}$} & \multirow{2}{*}{$\begin{array}{l}\text { Initial oil } \\
\text { saturation }(\%)\end{array}$} & \multirow[b]{2}{*}{ Chemical formula } & \multicolumn{3}{|c|}{ Recovery (\%) } \\
\hline & & & & & $\begin{array}{l}\text { Water } \\
\text { flooding }\end{array}$ & $\begin{array}{l}\text { Chemical } \\
\text { flooding }\end{array}$ & Total \\
\hline 1 & 36.0 & 1346 & 90.7 & $0.1 \% \mathrm{NaBO}_{2}$ & 29.2 & 1.5 & 30.7 \\
\hline 2 & 37.4 & 1624 & 89.0 & $0.3 \% \mathrm{NaBO}_{2}$ & 28.9 & 10.4 & 39.3 \\
\hline 3 & 38.9 & 1427 & 90.2 & $0.5 \% \mathrm{NaBO}_{2}$ & 29.6 & 15.4 & 45.0 \\
\hline 4 & 37.1 & 1472 & 89.2 & $0.7 \% \mathrm{NaBO}_{2}$ & 30.2 & 24.8 & 55.0 \\
\hline 5 & 35.3 & 1570 & 89.3 & $1.0 \% \mathrm{NaBO}_{2}$ & 29.7 & 27.1 & 56.8 \\
\hline 6 & 35.8 & 1428 & 90.2 & $0.1 \% \mathrm{NaBO}_{2}+0.02 \% \mathrm{NaOH}+0.06 \%$ PAPEMP & 29.8 & 2.3 & 32.1 \\
\hline 7 & 37.5 & 1472 & 90.4 & $0.19 \% \mathrm{NaBO}_{2}+0.04 \% \mathrm{NaOH}+0.12 \%$ PAPEMP & 29.6 & 17.3 & 46.9 \\
\hline 8 & 36.1 & 1428 & 90.4 & $0.29 \% \mathrm{NaBO}_{2}+0.06 \% \mathrm{NaOH}+0.18 \%$ PAPEMP & 30.0 & 21.7 & 51.7 \\
\hline 9 & 37.0 & 1472 & 90.8 & $0.48 \% \mathrm{NaBO}_{2}+0.10 \% \mathrm{NaOH}+0.29 \%$ PAPEMP & 29.2 & 25.3 & 54.5 \\
\hline 10 & 37.0 & 1309 & 89.0 & $0.67 \% \mathrm{NaBO}_{2}+0.14 \% \mathrm{NaOH}+0.41 \%$ PAPEMP & 29.1 & 35.1 & 64.2 \\
\hline 11 & 37.4 & 1273 & 89.1 & $0.86 \% \mathrm{NaBO}_{2}+0.18 \% \mathrm{NaOH}+0.52 \%$ PAPEMP & 30.2 & 43.2 & 73.4 \\
\hline
\end{tabular}

The displacement effects were evaluated under different sodium metaborate concentrations, as shown in Figure 2. The results indicated that with concentrations ranging from $0.3 \%$ to $1.0 \%$, all of the sodium metaborate systems showed good displacement effects. The maximum incremental value of oil recovery reached as high as $27.1 \%$ when the sodium metaborate concentration was $1.0 \%$. Compared to the pure sodium metaborate, the displacement effect of the PAPEMP alkaline system is better because of higher alkalinity. The enhanced oil recovery is as high as $43.2 \%$ for the $9 \%$ PAPEMP system. The figure 3 showed the $\mathrm{pH}$ of two system. 


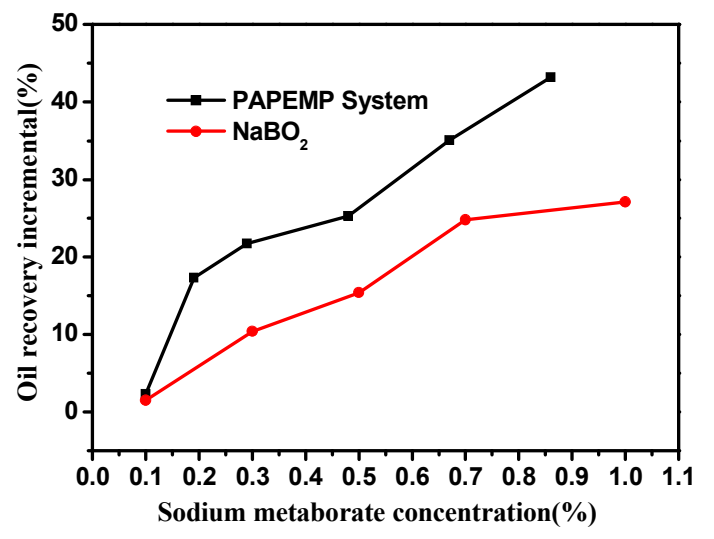

Figure 2. Comparison of oil recovery enhancement between $\mathrm{NaBO}_{2}$ flooding and PAPEMP system flooding.

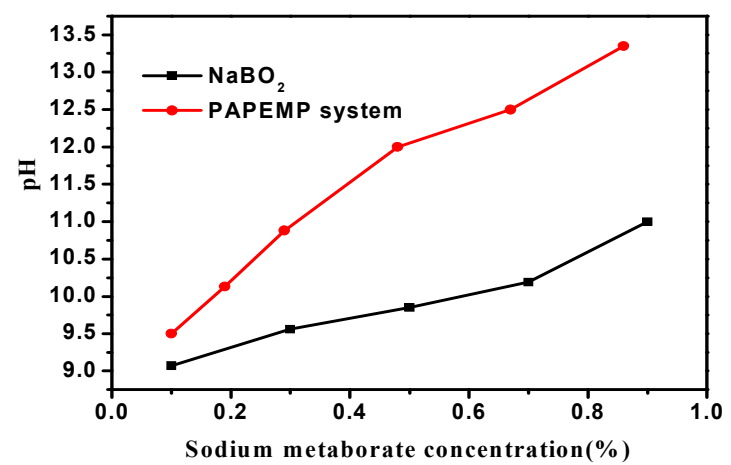

Figure 3. The $\mathrm{pH}$ of the two systems.

Figure 4 shows that Dynamic interfacial tension equilibrium value between the PAPEMP alkaline system and the crude oil is about $6 \sim 8 \times 10^{-2} \mathrm{mN} / \mathrm{m}$ and the effect of PAPEMP alkaline system on the reduction of the oil-water interfacial tension is not satisfactory, which illustrates that the mechanism of PAPEMP alkaline system for enhancing oil recovery does not act by improving the displacement efficiency. In general, because the viscosity of heavy oil is much higher than that of water, serious fingering phenomena occur during the waterflooding process. Yet A high pressure response occur when the alkaline concentration is high after the injection of PAPEMP suggests that it has a blocking effect on the water channel, which forces the injected water to the oil-rich area, thus enhancing the sweep efficiency, as shown in Figure 5.

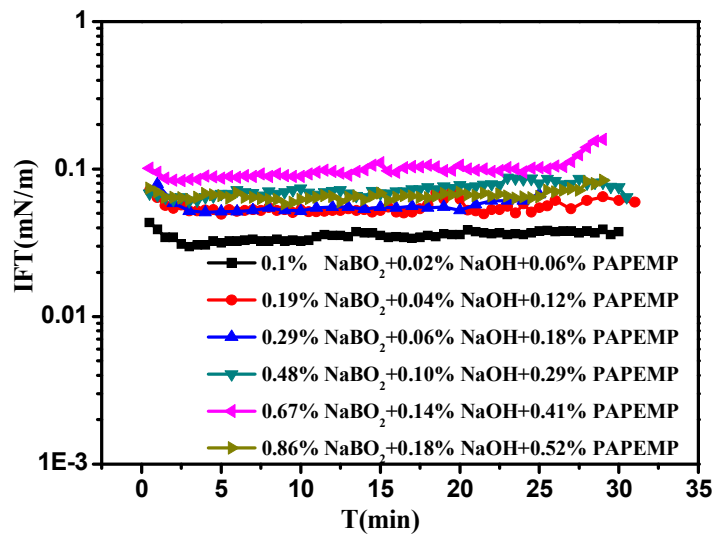

Figure 4. Dynamic IFT curves of PAPEMP system/heavy oil.

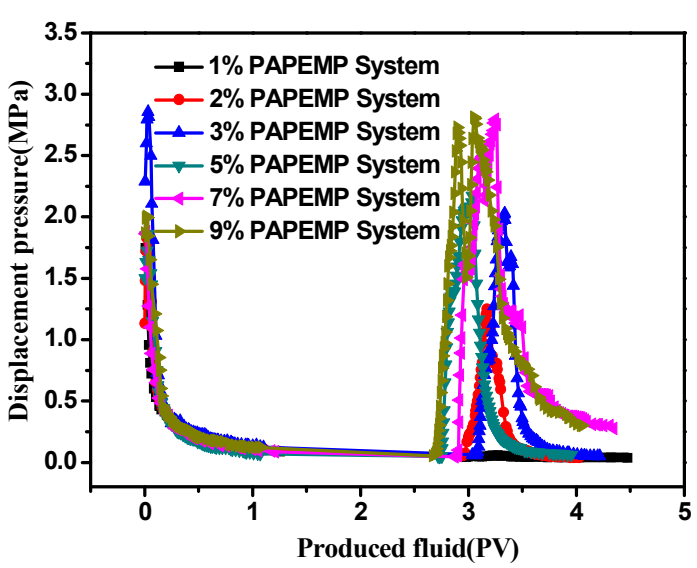

Figure 5. Pressure changes during PAPEMP alkaline system flooding.

To further determine the mechanisms of PAPEMP alkaline system blocking in the high permeability zone, the seepage behavior of 5\% PAPEMP system solution in porous medium is investigated utilizing a microscopic visual model test, and the results are shown in Figure 6.

Figure 6A shows the alkaline solution penetrated into the crude oil and created many water drops inside the oil phase (brown in color). The phenomenon of the formation of the water drop inside the oil phase during alkaline flooding is ascribed to the interfacial reaction between the alkali and the oil [10]. More water droplets are formed for the PAPEMP alkaline system since its interfacial reaction with the crude oil is acuter. A W/O emulsion bank eventually forms(see Figure $6 \mathrm{~B})$, which can be also shown in Figure 7. The viscosity of a $\mathrm{W} / \mathrm{O}$ emulsion is much higher than the viscosity of the water phase and even higher than the viscosity of the oil phase [11], which lead to the significant increase of the resistance to flow of the alkaline solution in the porous media. It has a blocking effect on the water channel, which forces the injected water to the oil-rich area, thus enhancing the sweep efficiency.

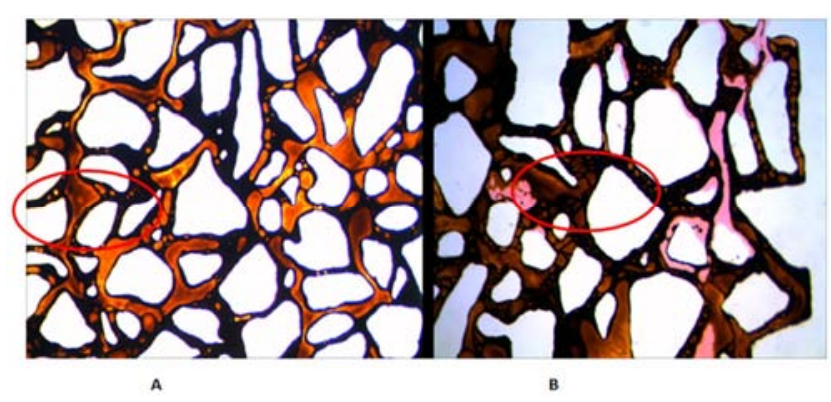

Figure 6. Images from the micromodel test.

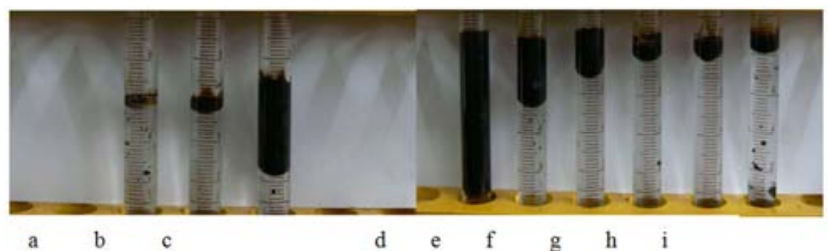

Figure 7. Produced fluid image of 5\% PAPEMP alkaline system (a-c: effluents during alkali injection; $d-k$ : effluents during the extended waterflooding; the pictures show their appearances at the end of flooding, without demulsification) 


\section{Conclusions}

The antiscaling effect of the PAPEMP alkaline system is better than the PASP alkaline system in the condition of $50^{\circ} \mathrm{C}$. When the concentration of the PAPEMP alkaline system is larger than $4 \%$, it could tolerate the solution with calcium ion concentration of $500 \mathrm{mg} / \mathrm{L}$ without scaling. The sandpack tests show that both pure sodium metaborate and the PAPEMP alkaline system have well displacing effect for the conventional heavy oil and the enhanced oil recovery increases with the increase of the alkaline concentration. Due to the higher alkaline of the PAPEMP alkaline system, it has higher oil recovery. In addition, microscopic visual model test reveals that alkaline solution is easy to ducking into the crude oil to form separate water droplets. More water droplets are formed for the PAPEMP alkaline system since its interfacial reaction with the crude oil is acuter. These water droplets are transformed to $\mathrm{W} / \mathrm{O}$ emulsions to block the high permeability channels, thus improving the sweep efficiency, accordingly to enhance the oil recovery. The formation of the $\mathrm{W} / \mathrm{O}$ emulsions during the alkaline flooding is the main mechanism to improve the heavy oil recovery.

\section{References}

[1] K. Miller, Petroleum society's 6th Canadian international petroleum conference, Calgary, Alberta, Canada. 2005: 251.

[2] Selby R, Alikhan A A, Farouq Ali S M. Potential of non-thermal methods for heavy oil recovery [J]. Journal of Canadian Petroleum Technology, 1989, 28(4):45-59.
[3] Hongchen Che, Yaoyu Ren, Hanping Liu, etal. Laboratory study on oil displacement with active water in Longhupao Oilfield [J]. Lithologic Reservoirs, 2011, 23(2):128-132.

[4] M. Arhuoma, D. Yang, M. Dong, R. Idem. Determination of Increase in Pressure Drop and Oil Recovery Associated with Alkaline Flooding for Heavy Oil Reservoirs[C]. in: Canadian International Petroleum Conference, Calgary, Alberta, 16-18 Jun, 2009.

[5] H. Y. Jennings, C. E. Johnson, C. D. McAuliffe. A caustic waterflooding process for heavy oils, J. Pet. Tech. 26(1974) 1344-1352.

[6] Berger P D, Lee C H. Improved ASP Process Using Organic Alkali[C]. SPE 99581-MS, 2006.

[7] Flaaten A K, Nguyen Q P, Zhang Jieyuan, et al. ASP Chemical flooding without the need for soft water[R]. SPE 116754,2008.

[8] Zhang Jieyuan, Quoc P. Nguyen, Adam K. Flaaten, et al. Mechanisms of Enhanced Natural Imbibition With Novel Chemicals [J]. SPE 113453-PA, 2009.

[9] Mingguang Tang, Guicai Zhang, etal. Investigation into the mechanisms of heavy oil recovery by novel alkaline flooding [J]. Colloids and Surfaces A: Physicochem. Eng. Aspects, 2013, 421:91-100.

[10] H. Pei, G. Zhang, J. Ge, L. Jin, X. Liu. Analysis of Microscopic Displacement Mechanisms of Alkaline Flooding for Enhanced Heavy-Oil Recovery, Energy Fuels, 2011, 25 (10):4423-4429.

[11] Zhang H, Dong M, Zhao S. Which one is more important in chemical flooding for enhanced court heavy oil recovery, lowering interfacial tension or reducing water mobility? [J]. Energy Fuels, 2010, 24(3):1829-1836. 